\title{
Fenugreek seeds, a hepatoprotector forage crop against chronic $\mathrm{AlCl}_{3}$ toxicity
}

\author{
Yosra Belaïd-Nouira ${ }^{1 *}$, Hayfa Bakhta ${ }^{1}$, Zohra Haouas ${ }^{1}$, Imen Flehi-Slim', Fadoua Neffati ${ }^{2}$, \\ Mohamed Fadhel Najjar ${ }^{2}$ and Hassen Ben Cheikh ${ }^{1}$
}

\begin{abstract}
Background: Having considered how bioavailable aluminium (Al) may affect ecological systems and animals living there, especially cattle, and in search for a preventive dietary treatment against Al toxicity, we aimed to test the protective role of fenugreek seeds against chronic liver injury induced by aluminum chloride $\left(\mathrm{AlCl}_{3}\right)$ in Wistar rats.

Results: Five months of $\mathrm{AlCl}_{3}$ oral exposure $(500 \mathrm{mg} / \mathrm{kg}$ bw i.g for one month then 1600 ppm via drinking water) caused liver atrophy, an inhibition of aspartate transaminase (AST), alanine transaminase (ALT) and glutamyl transpeptidase (GGT), an enhancement of both lipid peroxidation and lactate dehydrogenase (LDH) activity and an increase of total protein level in liver. Moreover, histopathological and histochemical examinations revealed moderate alterations in the hepatic parenchyma in addition to a disrupted iron metabolism. Co-administration of fenugreek seed powder (FSP) at 5\% in pellet diet during two months succeeded to antagonize the harmful effects of $\mathrm{AlCl}_{3}$ by restoring all tested parameters.

Conclusion: This study highlighted the hepatotoxicity of $\mathrm{AlCl}_{3}$ through biochemical and histological parameters in one hand and the hepatoprotective role of fenugreek seeds on the other hand. Thus this work could be a pilot study which will encourage farmers to use fenugreek seeds as a detoxifying diet supplement for domestic animals.
\end{abstract}

Keywords: $\mathrm{AlCl}_{3}$, Liver, Trigonella foenum-graecum, Lipid peroxidation, Histopathology, Iron metabolism

\section{Background}

Pollution with the potentially toxic ionic aluminium (Al) is becoming a serious ecological problem related mostly to soil and water acidification caused by acid rain and anthropogenic activities such as overgrazing and overuse of nitrogen and phosphate fertilizers [1]. Indeed, it is well documented that $\mathrm{Al}$ dissolves in acid environments which makes it more bioavailable and toxic [2]. Adverse effects caused by high $\mathrm{Al}$ levels have been in fact observed in plants and many domestic and wild-life species [3]. Al has also been involved in the etiology of grass tetany, a fatal neuromuscular disease in sheep, goats, and cows $[4,5]$. Grass tetany is a complex metabolic disorder characterized by hypomagnesemia resulting from mineral imbalances in the diet of ruminants [6]. Postmortem analyses of rumen contents of cattle who died from grass tetany revealed very high $\mathrm{Al}$ contents [7]. It is

\footnotetext{
* Correspondence: yosrabelaid@gmail.com

'Laboratory of Histology and Cytogenetic (Research unit of Genetic 02/UR/ 08-03), Faculty of Medicine, Avenue Ibnou Sina 5000, Monastir, Tunisia Full list of author information is available at the end of the article
}

likely that this disease involves the ability of dietary $\mathrm{Al}^{3+}$ to depress serum $\mathrm{Mg}^{2+}$ levels in ruminants and its toxic actions in $\mathrm{Mg}^{2+}$ metabolism [8]. This has led agricultural scientists to conclude that, if exposure conditions are sufficient, such mineral imbalances in the soil or forage could cause grass tetany. Thus, $\mathrm{Al}$ toxicity in cattle was associated with excessive intake of the metal in the diet or contamination of pastures by acidified soils and waters because crops grown on these soils may accumulate high levels of $\mathrm{Al}$ [1].

Starting from the fact that chronic exposure to $\mathrm{Al}$ is becoming a serious possibility for domestic animals, we aimed to test the ability of fenugreek seeds, a forage crop used as a dietary supplement, to counteract $\mathrm{Al}$ toxicity in Wistar rats. In the present study, we focused on the effect of $\mathrm{AlCl}_{3}$ on the liver owing to its important role as a detoxifying organ in one hand, and its vulnerability related to its involvement in $\mathrm{Al}$ absorption and excretion through biliary flux [9], on the other hand.

Fenugreek (Trigonella foenum-graecum L., Fabaceae) is an annual legume crop widely cultivated in Asia, Africa

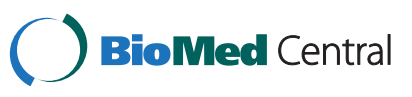

(c) 2013 Belaïd-Nouira et al.; licensee BioMed Central Ltd. This is an Open Access article distributed under the terms of the Creative Commons Attribution License (http://creativecommons.org/licenses/by/2.0), which permits unrestricted use, distribution, and reproduction in any medium, provided the original work is properly cited. 
and the Mediterranean countries where it is often used for the edible and medicinal values of its seeds. In other countries like Canada and England, fenugreek is used for incorporation into short-term crop rotation [10] due to its high adaptability to dry climatic conditions, annual nature, and ability to fix atmospheric nitrogen in soil. Thus, fenugreek can enrich soil by fixing $\mathrm{N}$, with benefits to soil conservation and reducing the impact of soil borne pathogens [11]. Fenugreek also provides excellent forage to cattle and can be grown efficiently for hay or silage [12,13]. As a feed for livestock, it is regarded as a bloat free crop that contains growth promoting compounds such as steroids and diosgenin, which are not present in other forage legumes [14]. Current research on fenugreek, most carried for therapeutic purposes, has shown that it contains beneficial chemical constituents including steroidal sapogenins, fiber, galactomannans, antioxidants, and amino acids such as 4-hydroxyisoleucine which possess antidiabetic, antioxidative, hypocholesterolemic, hypoglycemic, anti-inflammatory, antiulcerogenic, antitumor and immunomodulatory properties [15].

The hepatoprotective effect of fenugreek seeds, mainly restricted to studies on ethanol toxicity and diabetes, has also been elucidated through the literature [16-19] but the role of fenugreek in liver against aluminum-induced changes has not so far been considered.

\section{Results}

\section{Liver weight and total protein level}

No significant difference for the body weight (BW) was observed as compared to the control group. However, a significant decrease in the whole liver weight $(22.9 \%$, $\mathrm{p}<0.001$ ) was observed in $\mathrm{AlCl}_{3}$-treated rats. On the other hand, FSP had no effect on the liver weight but succeeded to prevent significantly liver weight loss when administrated with $\mathrm{Al}(\mathrm{p}<0.001)$. To make a functional comparison of weight gain or loss, tissue weight per 100 $\mathrm{g}$ of body weight was calculated. Liver has also shown a significant weight decrease per $100 \mathrm{~g}$ of body weight in $\mathrm{AlCl}_{3}$-intoxicated group which was reduced to $15 \%$ ( $p<0.001)$. This relative decrease was lesser after fenugreek administration $(\mathrm{p}<0.001)$ (Figure 1$)$. With regard to the total protein level in liver, $\mathrm{AlCl}_{3}$ caused a marked increase when compared to the control $(+29.69 \%$; $p<0.001)$ and treatment with FSP was found effective to keep a normal value (Figure 2). Treatment with FSP alone had no effect on both liver weight and total protein level.

\section{Transaminases activities}

The activities of ALT and AST in both liver and plasma were significantly decreased in rats treated with $\mathrm{AlCl}_{3}$ (-36\%, $-36.89 \%$ and $-55.7 \%,-44.29 \%$ respectively). The administration of FSP with $\mathrm{AlCl}_{3}$ restored the normal level of plasmatic and hepatic ALT activity and succeeded to

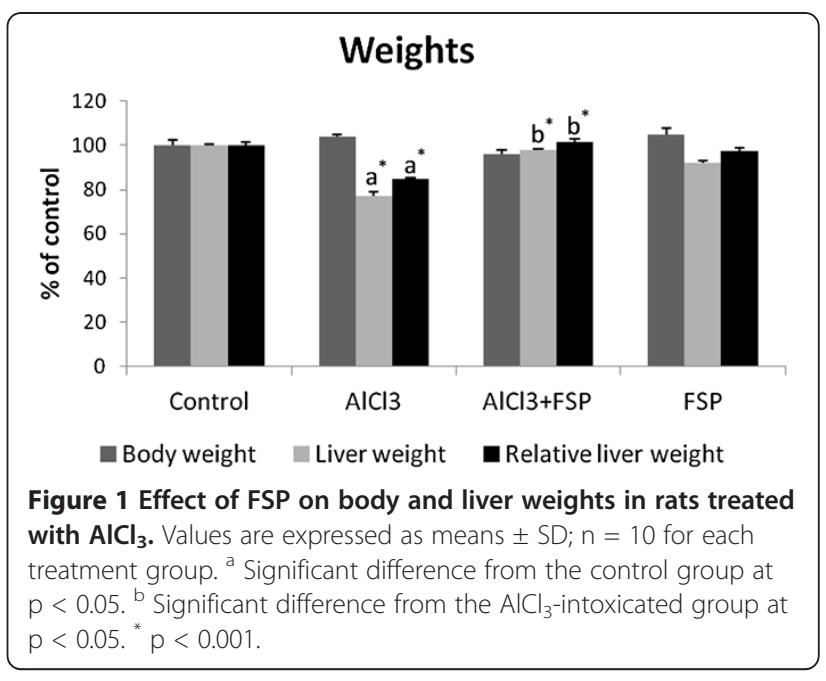

increase AST activity by $+7.1 \%$ in liver and $+7.6 \%$ in plasma (Figure 3 (a) and Figure 3 (b)).

\section{GGT activity as a cholestasis marker}

As it is shown in Figure 4, $\mathrm{AlCl}_{3}$ decreased GGT activity by $-33.67 \%$ ( $p<0.001$ ) but FSP supplementation ameliorated it registering an increase of $+21.9 \%(p<0.001)$.

\section{Plasma markers}

Data presented in Table 1 showed that treatment with $\mathrm{AlCl}_{3}$ caused a significant increase in blood glucose (+97.8\%; p <0.001). Given with $\mathrm{AlCl}_{3}$, FSP decreased plasma glucose to the normal value. On the other hand, a significant hypercholesterolemia together with a significant hypertriglyceridemia ( $\mathrm{p}<0.001$ ) were noticed during $\mathrm{AlCl}_{3}$ intoxication but fenugreek seeds were able to reestablish the normal values.

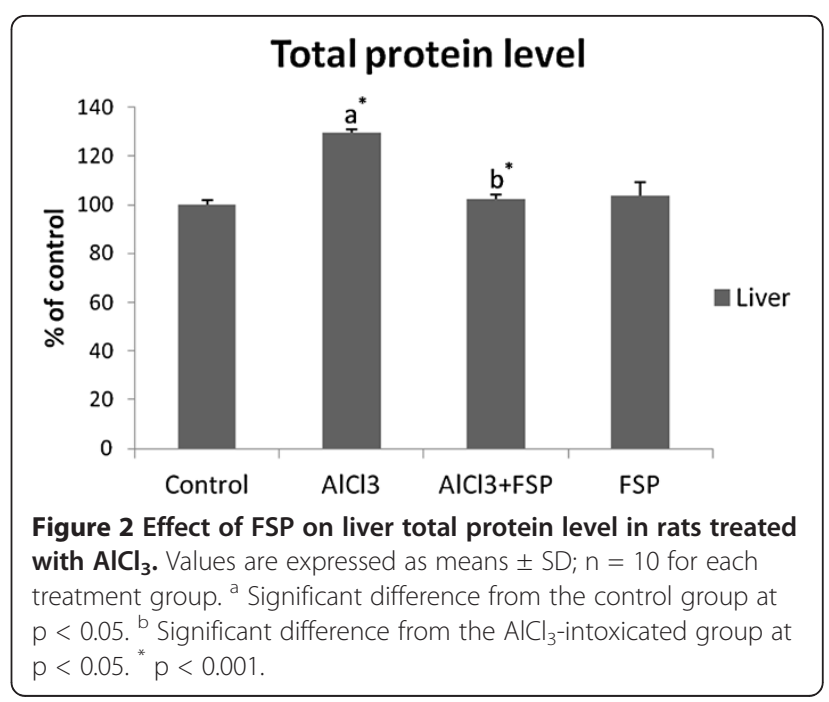




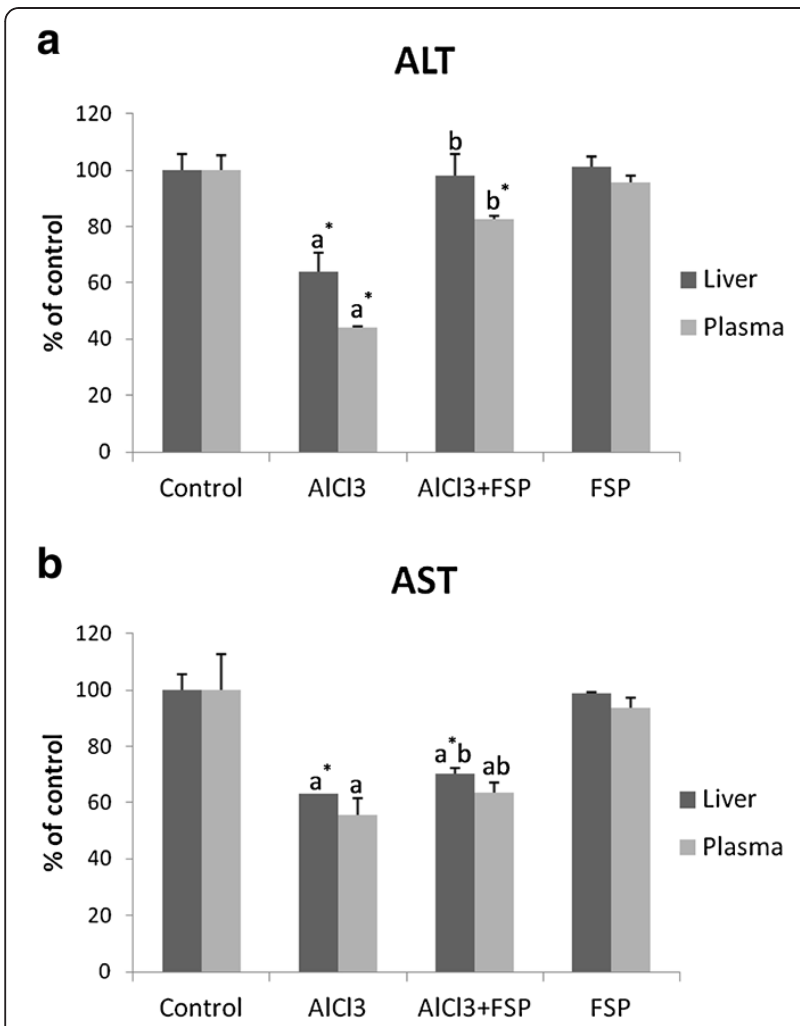

Figure 3 Effect of FSP on hepatic and plasmatic ALT and AST activities in rats treated with $\mathrm{AlCl}_{3}$. Values are expressed as means $\pm S D ; n=10$ for each treatment group. ${ }^{\text {a }}$ Significant difference from the control group at $\mathrm{p}<0.05$. ${ }^{\mathrm{b}}$ Significant difference from the $\mathrm{AlCl}_{3}$-intoxicated group at $\mathrm{p}<0.05 .{ }^{*} \mathrm{p}<0.001$.

\section{Lipid peroxidation estimation in liver tissue}

After $\mathrm{AlCl}_{3}$ administration, TBARS (Thiobarbituric Acid Reactive Substances) level was increased by $+44.6 \%$ compared to the controls and consecutively LDH activity raised by $+47.4 \%$. However, when FSP was given with

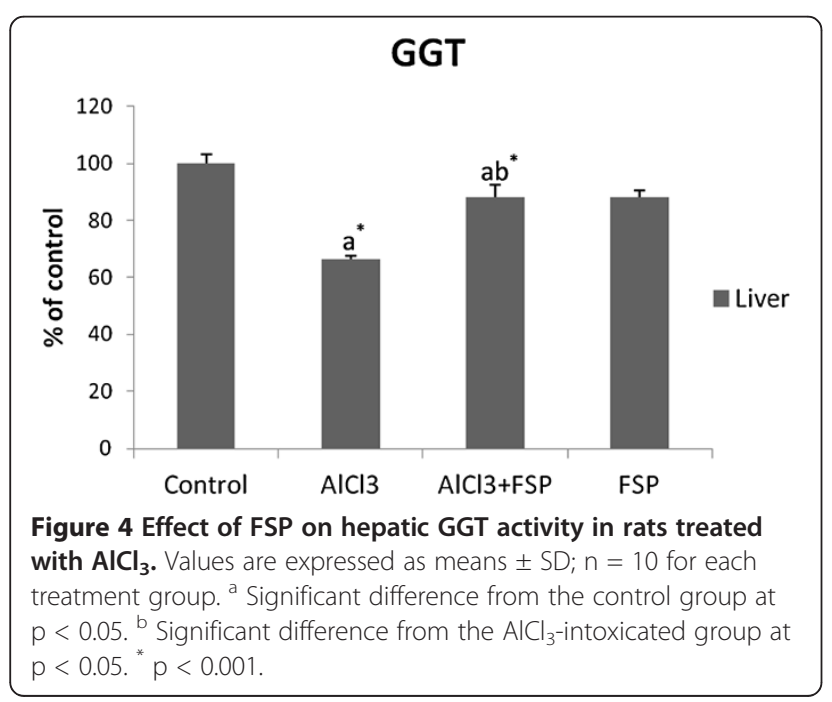

Table 1 Effects of FSP on some plasma markers (Glucose, cholesterol and triglycerides) in rats treated with $\mathrm{AlCl}_{3}$

\begin{tabular}{lcccc}
\hline Parameter & \multicolumn{5}{c}{ Experimental groups } & & \\
\cline { 2 - 5 } & Control & $\mathrm{AlCl}_{3}$ & $\mathrm{AlCl}_{3}+\mathrm{FSP}$ & FSP \\
\hline Glucose $(\mathrm{mmol} / \mathrm{l})$ & $8.39 \pm 0.03$ & $16.6^{\mathrm{a}^{*}} \pm 1.30$ & $8.18^{\mathrm{b}^{*}} \pm 0.08$ & $8.31 \pm 0.02$ \\
Cholesterol $(\mathrm{mmol} / \mathrm{l})$ & $1.56 \pm 0.009$ & $2.22^{\mathrm{a}^{*}} \pm 0.36$ & $1.56^{\mathrm{b}^{*}} \pm 0.01$ & $1.56 \pm 0.08$ \\
Triglycerides $(\mathrm{mmol} / \mathrm{l})$ & $0.66 \pm 0.02$ & $1.20^{\mathrm{a}^{*}} \pm 0.06$ & $0.58^{\mathrm{b}^{*}} \pm 0.02$ & $0.58 \pm 0.14$
\end{tabular}

Values are expressed as means $\pm S D ; n=10$ for each treatment group.

${ }^{a}$ Significant difference from the control group at $p<0.05$.

${ }^{\mathrm{b}}$ Significant difference from the $\mathrm{AlCl} 3$-intoxicated group at $\mathrm{p}<0.05$. * $p<0.001$.

$\mathrm{AlCl}_{3}$, we noticed a decrease of TBARS level by $-16.7 \%$ and LDH activity by $-42.9 \%$ (Figure 5 ).

\section{Histopathological and histochemical results}

Liver tissue from control rats (Figure 6 (a)) depicts a typical normal liver histology and hepatocyte structure with normal lobular architect and hepatocytes arranged in cords encircling the central canal. Similarly, sections of FSP-treated groups showed normal arrangement of hepatocytes and sinusoids. In rats administered $\mathrm{AlCl}_{3}$ (Figures 6 (b), 6 (c) and 6 (d)), the hepatic injury was marked by moderate hepatocellular necrosis randomly distributed throughout the parenchyma, as well as an increase in inflammatory cell infiltration, vascular congestion, pyknotic nuclei, moderate cytoplasmic vacuolation, granulous aspect of cytoplasm and dilated sinusoids. Changes were improved in FSP post-treated rats (Figures 6 (e) and 6 (f)), which exhibited areas of normal liver architecture, reduced cytoplasmic vacuolation and centrilobular necrosis in addition to normal sinusoidal spaces and less granulous aspect of cytoplasm. Groups treated with FSP after exposure to $\mathrm{AlCl}_{3}$ were also characterized by an increased number of bi-nucleated cells.

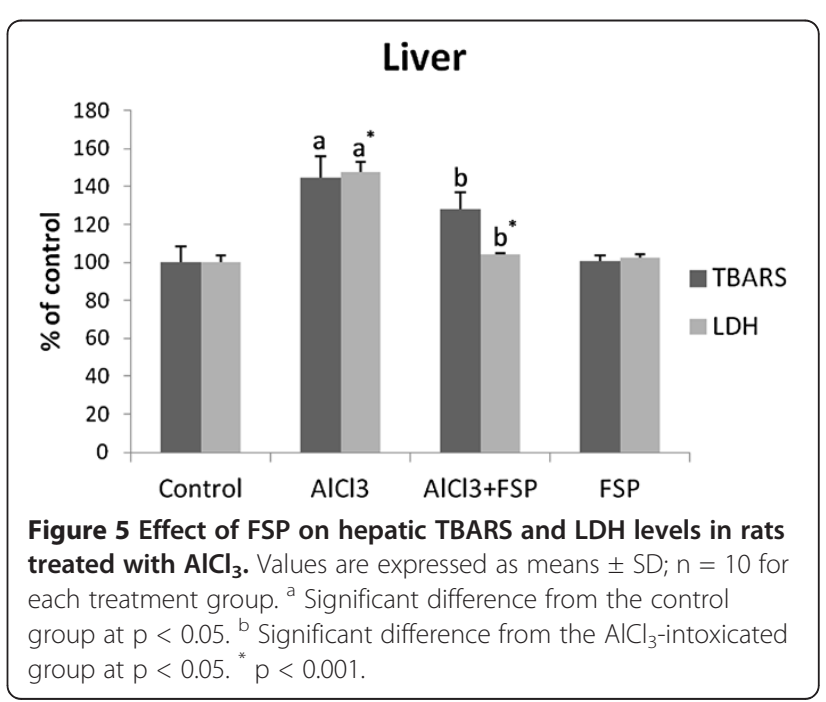




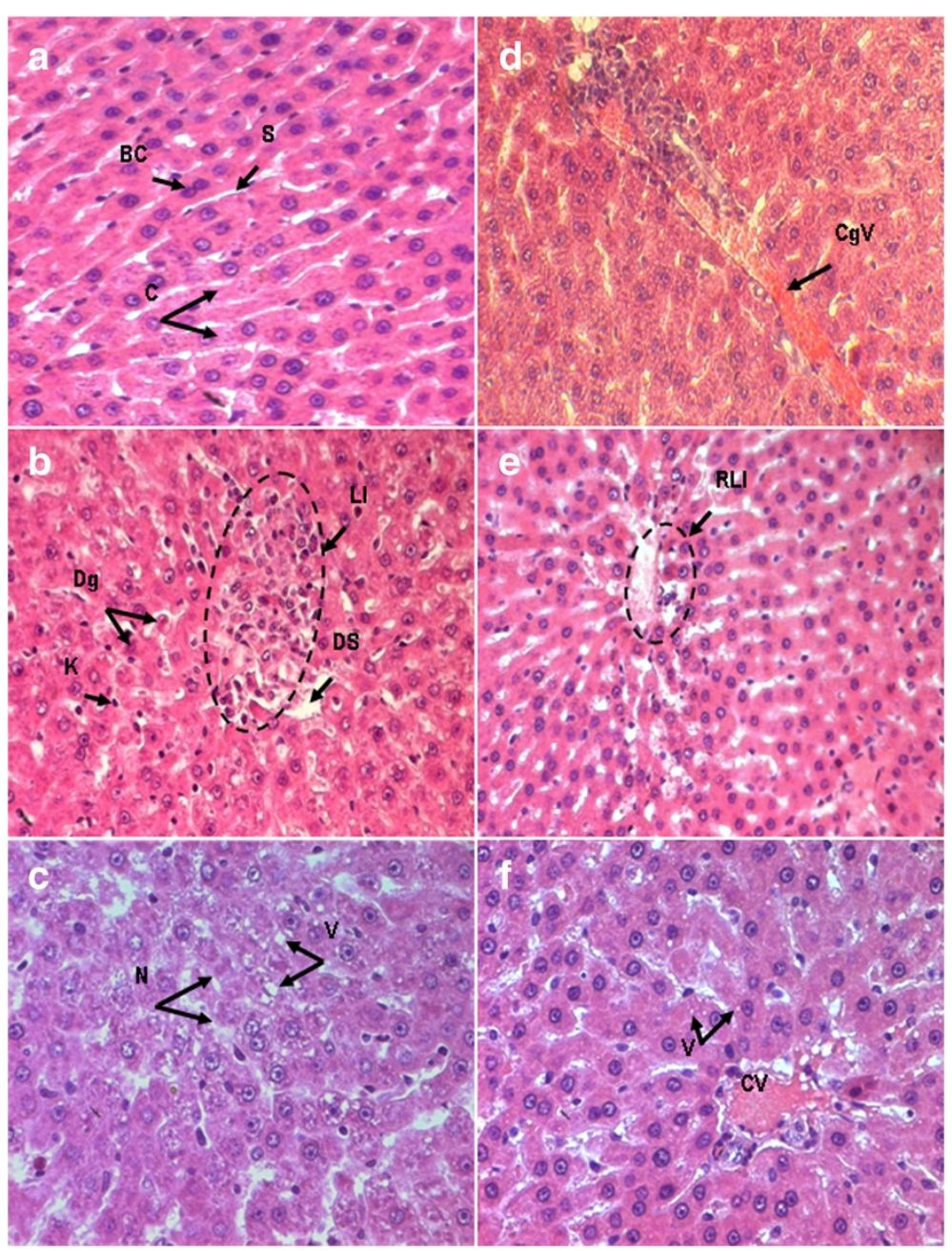

Figure 6 Light micrographs of rat liver tissue stained by hematoxylin-eosin (HE) in control (a)(x500), AICl 3 -treated group (b,c,d)(x320, x500, x500 respectively) and Fenugreek+AICl 3 -treated group (e, f) (x320, x500 respectively). C: hepatic cords, BC: binucleated cell, S: sinusoids, Dg: degenerating cell, K: Kupffer cell, DS: dilated sinusoid, LI: lymphoid infiltrate, N: necrotic cells, V: vacuoles, CgV: congested vein, $\mathrm{CV}$ : central vein.

Iron distribution in paraffin sections of rat liver stained with Perl's is illustrated in Figure 7. Section of control hepatic parenchyma (Figure 7 (a)) showed a slight deposition of iron in liver tissue homogeneously distributed. Hepatocytes localized around the central vein and around portal areas accumulated a larger quantity of iron. After $\mathrm{Al}$ intake, an abnormal and more pronounced Perl's positive iron deposition was detected in pericentral and parenchymal cells compared to the control group (Figure 7 (b)). Treatment with FSP restored the normal aspect of iron distribution (Figure 7 (c)).

\section{Discussion}

In Al-treated animals, the hepatic weight loss is an indicator of $\mathrm{Al}$ toxicity as it was mentioned in another report [20]. It may be due to enhanced catabolic processes such as glycogenolysis, lipolysis or proteolysis, which is the outcome of lack of cellular glucose in liver cells. The disturbance of the catabolic process in the liver was evidenced in this study by a significant hyperglycemia and an altered lipid metabolism (hypercholesterolemia and hypertriglyceridemia). Besides, liver atrophy could be understood if we consider the similarities of Al hepatotoxicity to the aging process evoked by Stacchiotti et al. (2008) [21]. In fact, a positive relationship between smaller organ mass and senescence has been proven [22].

On the other hand, a remarkable increase of hepatic total protein level was noticed. This is because Al, like other toxic metals, may affect intracellular processing of secreted proteins and also retard their discharge, resulting in the inhibition of protein secretion from liver parenchymal cells [23]. This result may explain the decrease of plasma total proteins in rats intoxicated by $\mathrm{AlCl}_{3}$ recorded in other reports [24,25]. Moreover, based on 


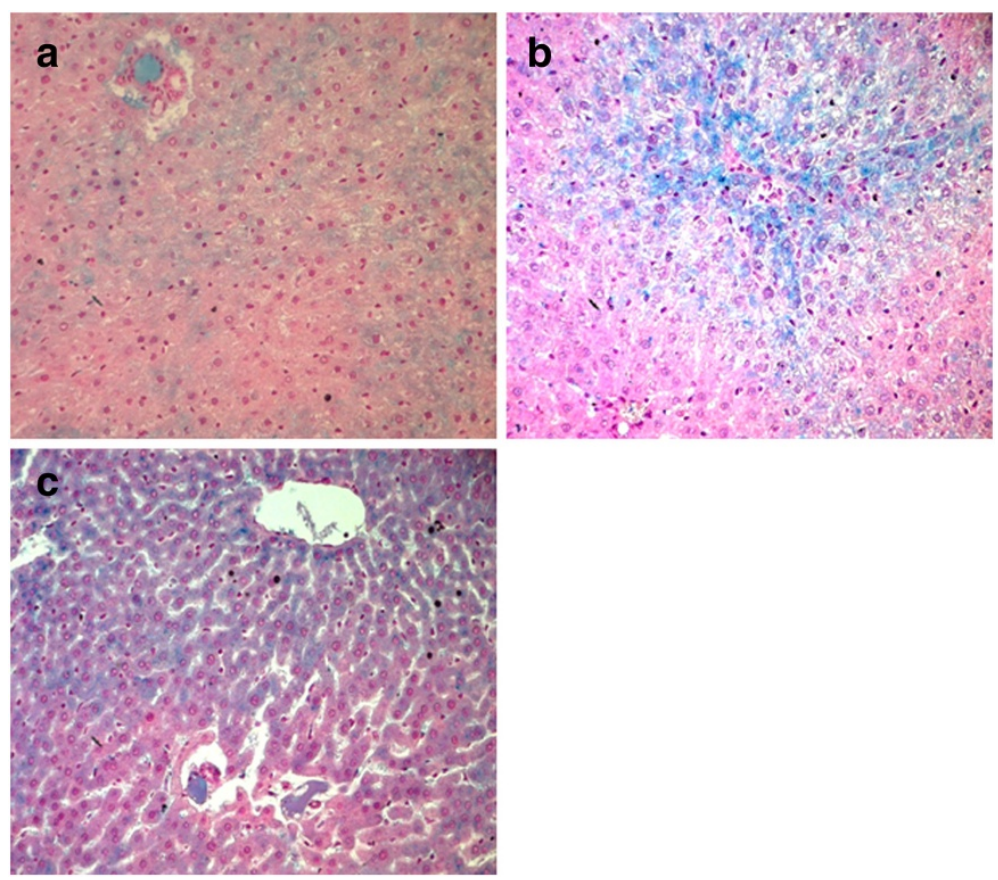

Figure 7 Light micrographs of Perl's staining of rat liver tissue in control (a), $\mathrm{AlCl}_{3}$-treated group (b) and Fenugreek+AICl 3 -treated group (c) (x100).

the correlation established by Stacchiotti et al. (2008) between Al toxicity and liver aging [21], this result could also be explained by the increase in total protein synthesis, typical to advanced age, which may be due to a compensation by the liver for a more pronounced proteinuria, increased proteolysis or an accumulation of "altered" proteins [26]. This was evidenced in this study by the elevation of intra-hepatic LDH. Within this context, it was reported that $\mathrm{Al}$ was able to enhance the synthesis of some stress proteins (HSP 72 and GRP 75) in liver after chronic exposure [27].

The concomitant treatment of rats by FSP succeeded to prevent liver weight loss and was able to reduce total protein level probably due to fenugreek seeds capacity to correct both glucose and lipid metabolism and prevent lipid peroxidation as it was shown in this study and may be modulating the repair protein battery. The role of a possible regenerative process could also be considered [28].

Regarding histopathological changes induced by $\mathrm{AlCl}_{3}$ in liver, it is assumed that $\mathrm{Al}$ exposure can result in $\mathrm{Al}$ accumulation in liver cells [29], where it produces dosedependent cytotoxic effects [30]. Our results demonstrated that $\mathrm{AlCl}_{3}$ caused structural changes in the liver tissue of Wistar rats recalling those generated by other hepatotoxins [31]. Al treatment generated cytoplasmic vacuolation evoking the hepatosteatosis, known by an excess of lipids accumulation in cytoplasmic vesicles. In fact, it was found that Al toxicity enhances lipid accretion in hepatocytes [32] due to the impairment of lipid metabolism as it was shown by the increase of both total cholesterol and triglycerides and particularly the increase of lipid peroxidation as it was evidenced by increased hepatic TBARS (Thiobarbituric Acid Reactive Species) level. Besides, the granular aspect of the cytoplasm after $\mathrm{AlCl}_{3}$ treatment could be the consequence of hemosiderin deposit, as attested by Perl's staining performed in this study and other reports [21]. Hemosiderin accumulation is in fact a result of iron metabolism impairment as a consequence of $\mathrm{AlCl}_{3}$ toxicity [33].

Against all these pathological changes induced by $\mathrm{AlCl}_{3}$ in liver tissue, FSP administration was found effective. Indeed, we noticed a reduction in the size of inflammatory cell infiltration areas attributable to the proven anti-inflammatory activity of Trigonella [34] and a reduction in the number of necrotic cells. Interestingly, it has been shown that methanol fenugreek seed extract was able to decrease 3-NT (3-nitrotyrosine) immunostaining, a marker of protein damage and a biomarker of inflammation, following ethanol toxicity in vivo [16]. The ability of fenugreek to prevent necrosis was already proven in primary rat hepatocytes culture against $\mathrm{N}$ methyl-N_-nitro-N-nitrosoguanidine (MNNG) toxicity [35]. A reduction of lipid vacuoles was also observed in this study, which reflects an improvement of lipid metabolic disorders generated by $\mathrm{AlCl}_{3}$ especially the decrease of lipid peroxidation. Interestingly, we found that liver section of Al-intoxicated rats treated by fenugreek exhibited increased mitosis giving evidence 
of a regenerative process that might be related to an effect on interleukin-6 [28].

In parallel with histopathological evaluation, liver function tests were carried out. $\mathrm{Al}$ has been known to increase plasmatic levels of AST and ALT in association with cellular degeneration of the liver [24,25]. Unexpectedly, we noticed a decrease of ALT and AST levels in liver homogenates that did not reflect its escape to blood because their plasmatic levels decreased too. Moreover, histological alterations were not enough drastic to cause a complete depletion of these enzymes. Consequently, it seems that 5 months of $\mathrm{AlCl}_{3}$ treatment have inhibited ALT and AST activities. Transaminases inhibition has been described in other reports as a mechanism of toxicity of some chemicals such as fenthion [36], ethanol [37], hydrazine [38] or acetaldehyde [39]. This result, although unexpected, supports the postulate that inhibition of transamination might play a role in the chronic $\mathrm{AlCl}_{3}$ toxicity on protein and carbohydrate metabolisms as previously demonstrated [24]. In fact, it was published that $\mathrm{Al}$ ions could inhibit pyridoxal phosphate catalyzed decarboxylation and transamination in vitro [40] and it is worthwhile to mention that ALT and AST are pyridoxal phosphate (PLP)-dependent transaminase enzymes.

As a marker of cholestasis, liver GGT was assayed. Specific to biliary ducts, these enzymes are expected to decrease pathologically in liver tissue. In the present study, a significant decrease was observed in intra-hepatic GGT activity, which means that 5 months of $\mathrm{AlCl}_{3}$ intoxication could cause cholestasis.

With regard to the protective role of fenugreek seeds against $\mathrm{AlCl}_{3}$-induced changes in biochemical parameters, it is upheld that FSP can ameliorate hepatic function through the significant amelioration of ALT and AST activities in the liver and plasma as well as the prevention of cholestasis.

Then again, the increased levels of TBARS suggest that $\mathrm{AlCl}_{3}$ exerts a significant oxidative stress through lipid peroxidation on liver tissue. This result is perfectly concordant with other reports which elucidated lipid peroxidation as a major mechanism of $\mathrm{Al}$ salts toxicity in the liver and other organ cells [25,41]. Increased lipid peroxidation could be a result of various mechanisms such as affecting the activity of antioxidant enzymes [42], inducing glucotoxicity through pancreatic beta-cell dysfunction and insulin resistance [43] or disturbing cellular metal homeostasis especially that of iron [44]. Knowing that iron is stored mostly in the liver as ferritin or hemosiderin, Perl's staining was performed. In this study, Al reduced liver iron stores and caused an abnormal and diffused iron hemosiderin Prussian blue deposit within pericentral lobular hepatocytes. This could be related to altered cellular homeostasis of iron already proven [45]. Indeed, $\mathrm{Al}$ ions could replace iron and magnesium ions in the biological systems leading to $\mathrm{Al}$ overloading in different organs. Free iron ions are able to initiate cellular damage [46]. Al could also enhance iron uptake into ferritin, the major iron storage protein localized in the liver together with transferrin receptors, and its conversion to hemosiderin [45]. Our histochemical results are concordant with earlier published data [21,27].

FSP was able to protect liver from lipid peroxidation induced by $\mathrm{AlCl}_{3}$. It is likely that lipid peroxidation in the liver is owing to the antiradical and antioxidant potential of Trigonella seeds emphasized through in vitro and in vivo experiments [16,47-50]. Fenugreek seeds are in fact rich in polyphenolic flavonoids $(>100 \mathrm{mg} / \mathrm{g}$ ) [51] and recently quercetin, one of the identified flavonoids in fenugreek seeds, was found able to protect rat hepatocytes against oxidative damage induced by ethanol [52] The well known hypoglycemic property of fenugreek seeds could also be behind its anti-peroxidative action in liver as it was proven during diabetes [53]. The effect of fenugreek seeds on iron metabolism might also be proposed as a hepatoprotector mechanism since FSP restored the normal iron distribution feature in liver. This result corroborates the findings of other authors who noticed the ability of the seed extract to prevent iron-induced lipid peroxidation in vitro [54].

\section{Conclusions}

Even if preliminary, this study has illustrated the curative role of fenugreek seeds against $\mathrm{Al}$-induced hepatotoxicity. This work is an additional result in favor of this multi-purpose plant. It could be a motivating work for farmers and industrials to incorporate at reasonable rates fenugreek seeds, cheap and easy to obtain, in livestock feed in order to protect cattle from chronic aluminium accumulation.

\section{Methods}

\section{Reagents}

Aluminum chloride $\left(\left(\mathrm{AlCl}_{3}, 6 \mathrm{H}_{2} \mathrm{O}\right)\right.$, analytical grade) was purchased from Sigma-Aldrich Chemical Co. (St. Louis, USA). All other chemicals were of analytical grade.

\section{Animals}

Wistar rats (weighing 208-220 g) were obtained from the Central Pharmacy (SIPHAT, Tunis, Tunisia). They were fed pellet diet purchased from the Industrial Society of Rodents' Diet (SICO, Sfax, Tunisia) and tap water ad libitum. Animals were kept in an air-conditioned room (temperature $22 \pm 3^{\circ} \mathrm{C}$ and relative humidity of $40 \%$ ) with a $12 \mathrm{~h}$ light/dark cycle. The experimental procedures were carried out according to the National Institute of Health Guidelines for Animal Care and approved by the local Ethics Committee (The Tunisian Association of Laboratory 
Animals Sciences (ATSAL, Visa 2007T02602APSF1 J.O.R. T. 27 April 2007 n³4. p 2115).

\section{Preparation of fenugreek seed powder (FSP)}

Trigonella seeds purchased from the local market were finely powdered and mixed at $5 \%$ in ground standard rat feed (i.e. $5 \mathrm{~g}$ of dry ground Trigonella seeds in $95 \mathrm{~g}$ of ground rat food). The dose of fenugreek seeds employed in this study was chosen according to previous studies and has been subjected to nutritional and safety evaluation [55].

\section{Study design}

Rats were treated according to the modified protocol established by Gong et al. [56]. In brief, rats were randomly distributed into four groups of ten animals each: control; $\mathrm{AlCl}_{3}$ daily during 5 months at the level of 500 $\mathrm{mg} / \mathrm{kg}$ bw i.g for one month then $1600 \mathrm{ppm}$ via drinking water; $\mathrm{AlCl}_{3}$ plus fenugreek seed powder at $5 \%$ in standard rat food (FSP) during the last 2 months and FSP alone.

\section{Blood and tissue collection}

Blood samples were collected under anesthesia by cardiac puncture in heparinized tubes. Plasma was obtained by centrifuging the blood at 3,000 $x g$ for 15 min at $4^{\circ} \mathrm{C}$ and stored in aliquots at $-20^{\circ} \mathrm{C}$ until analysis. Livers were removed quickly from animals, washed in ice-cold physiological saline and weighed. Then, multiple lobes of the liver from each rat were cut out. Some of them were fixed in Bouin's fluid and embedded in paraffin; others were minced and homogenized $(10 \% \mathrm{w} / \mathrm{v})$ separately in ice-cold $1.15 \% \mathrm{KCl}-0.01 \mathrm{~mol} / \mathrm{L}$ sodium, potassium phosphate buffer (pH 7.4) in a Potter-Elvehjem type homogenizer. The homogenate was centrifuged at $10,000 \times \mathrm{g}$ for $20 \mathrm{~min}$ at $4^{\circ} \mathrm{C}$, and the resultant supernatant was stored at $-80^{\circ} \mathrm{C}$ to be used for different assays.

\section{Histological studies}

Cross sections of paraffin-embedded livers were cut ( $5 \mu \mathrm{m}$ thicknesses) and stained with either hematoxylin and eosin (HE) for light microscopy examination [57] or Perl's reagent to reveal iron distribution [58].

\section{Biochemical assays}

\section{Assays of liver and plasma markers}

Total proteins, ALT, AST, GGT, total cholesterol, triglycerides, LDH and glycemia, were determined using enzymatic methods on Integra 400 plus $^{\text {TM }}$ (Roche Diagnostics, products references are \#03183734190, \#20764957322, \#207 64949322, \#03002721122, \#03039773190, \#20767107322, \#03004732122 and \#04404483190 respectively).

\section{Lipid peroxidation estimation}

The extent of lipid peroxidation in liver was assessed by measuring the content of thiobarbituric acid reactive substances (TBARS) following the method of Buege and Aust [59]. TBARS were expressed as malondialdehyde (MDA) amount using freshly diluted malondialdehyde bisdimethylacetal as standard.

\section{Statistical analysis}

Data were expressed as mean \pm standard deviation (SD) and analyzed using one-way analysis of variance (ANOVA) followed by the post hoc Tukey's test, used for comparison. Values were considered statistically significant when $\mathrm{p}<0.05$. Statistics were done using IBM SPSS Statistics 19.

\section{Competing interests}

The authors declare that they have no competing interests.

\section{Author's contributions}

YB-N conceived this study, designed it, analyzed and interpreted the data and wrote the manuscript. HB participated in the study design and data acquisition. $\mathrm{ZH}$ took the pictures of histological sections and interpreted them. FN has made substantial contributions in biochemical assays. IF-S carried out some of the plasmatic assays. MFN and HBC drafted and revised the manuscript. All authors read and approved the final manuscript.

\section{Acknowledgments}

This work was supported by the "Ministère Tunisien de l'Enseignement Supérieur, de la Recherche Scientifique et de la Technologie ». We acknowledge the significant contribution of all experts who participated in this study especially Dr. Oussama Ayara for English proofreading.

\section{Author details}

${ }^{1}$ Laboratory of Histology and Cytogenetic (Research unit of Genetic 02/UR/ 08-03), Faculty of Medicine, Avenue Ibnou Sina 5000, Monastir, Tunisia. ${ }^{2}$ Laboratory of Biochemistry-Toxicology, University Hospital of Monastir, Monastir, Tunisia.

Received: 28 September 2012 Accepted: 25 January 2013 Published: 31 January 2013

\section{References}

1. Walton JR: Bioavailable Aluminum: Its Metabolism and Effects on the Environment. In Encyclopedia of Environmental Health, volume 1. Edited by Nriagu JO. Burlington: Elsevier; 2011:331-342.

2. Driscoll CT, Postek KM: The Environmental Chemistry of Aluminium. Chelsea: Lewis; 1996:363-418.

3. Sparling DW, Lowe TP: Environmental hazards of aluminum to plants, invertebrates, fish, and wildlife. Rev Environ Contam Toxicol 1996, 145:1-127.

4. Allen $\mathrm{V}$, Robinson D, Hembry F: Aluminum in the etiology of grass tetany. J Anim Sci 1980, 51:44.

5. Dennis E: Magnesium deficiency and grass tetany. Fret Sol 1970, 15:44.

6. Mayland HF, Church DC Prentice-Hall: Grass tetany. In The ruminant animal: digestive physiology and nutrition. Edited by Church DC. Englewood Cliffs, N. J: Prentice-Hall; 1988:511-523.

7. Allen VG, Robinson DL: Occurrence of $\mathrm{Al}$ and $\mathrm{Mn}$ in grass tetany cases and their effects on the solubility of Ca and Mg in vitro. Agron J 1980, 72:957-960

8. Allen $V$, Robinson D, Hembry F: Effects of ingested aluminum sulfate on serum magnesium and the possible relationship to hypomagnesemic tetany. Nutr Rep Int 1984, 29:107-113.

9. Gonzalez MA, Alvarez MDL, Pisani GB, Bernal CA, Roma MG, Carrillo MC: Involvement of oxidative stress in the impairment in biliary secretory function induced by intraperitoneal administration of aluminum to rats. Biological Trace Element Res 2007, 116:329-348.

10. Mir Z, Acharya SN, Mir PS, Taylor WG, Zaman MS, Mears GJ, Goonewardene LA: Nutrient composition, in vitro gas production and digestibility of fenugreek (Trigonella foenum-graecum) and alfalfa forages. Can J Anim Sci 1997, 77:119-124 
11. Acharya S, Thomas J, Basu K: Fenugreek: an "old world" crop for the "new world". Biodiversity 2006, 7:27-30.

12. Mir PS, Mir Z, Townley-Smith L: Comparison of the nutrient content and in situ degradability comparisons of fenugreek ( Trigonella foenumgraecum) and alfalfa hays. Can J Anim Sci 1993, 73:993-996.

13. Mir Z, Mir RS, Acharya SN, Zaman MS, Taylor WG, Mears GJ, McAllister TA, Goonewardene LA: Comparison of alfalfa and fenugreek (Trigonella foenum-graecum) silages supplemented with barley grain on performance of growing steers. Can J Anim Sci 1998, 78:343-349.

14. Cao YC, Yang HJ: Ruminal digestibility and fermentation characteristics in vitro of fenugreek and alfalfa hay combination with or without the inoculation of Neocallimastix sp. YAK11. Anim Feed Sci Techno 2011, 169:53-60.

15. Satheeshkumar N, Mukherjee PK, Bhadra S, Saha BP: Acetylcholinesterase enzyme inhibitory potential of standardized extract of Trigonella foenum graecum L and its constituents. Phytomedicine: Int J Phytotherapy Phytopharmacology 2010, 17:292-295

16. Kaviarasan S, Sundarapandiyan R, Anuradha CV: Protective action of fenugreek (Trigonella foenum graecum) seed polyphenols against alcohol-induced protein and lipid damage in rat liver. Cell Biol Toxicol 2008, 24:391-400.

17. Eidi A, Eidi M, Sokhteh M: Effect of fenugreek (Trigonella foenum-graecum L) seeds on serum parameters in normal and streptozotocin-induced diabetic rats. Nutr Res 2007, 27:728-733.

18. Thakran S, Siddiqui MR, Baquer NZ: Trigonella foenum graecum seed powder protects against histopathological abnormalities in tissues of diabetic rats. Mol Cell Biochem 2004, 266:151-159.

19. Sushma N, Devasena T: Aqueous extract of Trigonella foenum graecum (fenugreek) prevents cypermethrin-induced hepatotoxicity and nephrotoxicity. Hum Exp Toxicol 2010, 29:311-319.

20. Yeh $Y-H$, Lee $Y-T$, Hsieh H-S, Hwang D-F: Effect of taurine on toxicity of aluminum in rats. e-SPEN, the European e-J Clin Nutr Metab 2009, 4:e187-e192.

21. Stacchiotti A, Lavazza A, Ferroni M, Sberveglieri G, Bianchi R, Rezzani R, Rodella LF: Effects of aluminium sulphate in the mouse liver: similarities to the aging process. Exp Gerontol 2008, 43:330-338.

22. He Q, Heshka S, Albu J, Boxt L, Krasnow N, Elia M, Gallagher D: Smaller organ mass with greater age, except for heart. J Appl Physiology (Bethesda, Md.: 1985) 2009, 106:1780-1784.

23. Borges LP, Brandão R, Godoi B, Nogueira CW, Zeni G: Oral administration of diphenyl diselenide protects against cadmium-induced liver damage in rats. Chemico-Biological Interactions 2008, 171:15-25.

24. Eldemerdash F: Antioxidant effect of vitamin $\mathrm{E}$ and selenium on lipid peroxidation, enzyme activities and biochemical parameters in rats exposed to aluminium. J Trace Elements Med Biol 2004, 18:113-121.

25. Newairy A-S A, Salama AF, Hussien HM, Yousef MI: Propolis alleviates aluminium induced lipid peroxidation and biochemical parameters in male rats. Food and chemical toxicology/: an international journal published for the British Industrial Biological Research Association 2009, 47:1093-1098.

26. Van Bezooijen CF, Grell T, Knook DL: The effect of age on protein synthesis by isolated liver parenchymal cells. Mech Ageing Dev 1977 6:293-304

27. Stacchiotti A, Rodella LF, Ricci F, Rezzani R, Lavazza A, Bianchi R: Stress proteins expression in rat kidney and liver chronically exposed to aluminium sulphate. Histol Histopathol 2006, 21:131-140.

28. Kaviarasan S, Viswanathan P, Anuradha CV: Fenugreek seed (Trigonella foenum graecum) polyphenols inhibit ethanol-induced collagen and lipid accumulation in rat liver. Cell Biol Toxicol 2007, 23:373-383.

29. Kametani K, Nagata T: Quantitative elemental analysis on aluminum accumulation by HVTEM-EDX in liver tissues of mice orally administered with aluminum chloride. Med Mole Morphol 2006, 39:97-105.

30. Roy AK, Talukder G, Sharma A: Similar effects in vivo of two aluminum salts on the liver, kidney, bone, and brain of Rattus norvegicus. Bull Environ Contam Toxicol 1991, 47:288-295.

31. Chouhan S, Lomash V, Flora SJS: Fluoride-induced changes in haem biosynthesis pathway, neurological variables and tissue histopathology of rats. J Appl Toxicol: JAT 2010, 30:63-73.

32. Lemire J, Mailloux R, Darwich R, Auger C, Appanna VD: The disruption of $\mathrm{L}$-carnitine metabolism by aluminum toxicity and oxidative stress promotes dyslipidemia in human astrocytic and hepatic cells. Toxicol Lett 2011, 203:219-226.
33. Han J, Dunn Ma: Effect of dietary aluminum on tissue nonheme iron and ferritin levels in the chick. Toxicology 2000, 142:97-109.

34. Thakur AM, Sarvaiya JG, Bhavsar SK: Studies on anti-inflammatory activities of Trigonella in rats. In Update Ayurveda. Bombay, India; 1994:75.

35. Khader M, Eckl PM, Bresgen N: Effects of aqueous extracts of medicinal plants on MNNG-treated rat hepatocytes in primary cultures. J Ethnopharmacol 2007, 112:199-202.

36. Altuntaş I, Delibaș N: The Effects of Fenthion on Lipid Peroxidation and Some Liver Enzymes: The Possible Protective Role of Vitamins E and C. Turkish J Med Sci 2002, 32:293-297.

37. Solomon LR: Evidence for the generation of transaminase inhibitor(s) during ethanol metabolism by rat liver homogenates: a potential mechanism for alcohol toxicity. Biochemical Med Metab Biol 1987, 38:9-18.

38. Stein ER, Clark DA, Fortney SR: Inhibition of glutamic-oxaloacetic transaminases of rat liver by hydrazine. Toxicol App/ Pharmacol 1971, 18:274-284.

39. Crouch JY, Solomon LR: Inhibition of rat liver transaminases by low levels of acetaldehyde and the pharmacologic effects of B6 vitamers. Biochem Pharmacol 1989, 38:3431-3437.

40. Zabinski RF, Toney MD: Metal ion inhibition of nonenzymatic pyridoxal phosphate catalyzed decarboxylation and transamination. J Am Chem Soc 2001, 123:193-198.

41. Yousef Ml: Aluminium-induced changes in hemato-biochemical parameters, lipid peroxidation and enzyme activities of male rabbits: protective role of ascorbic acid. Toxicology 2004, 199:47-57.

42. Türkez H, Yousef Ml, Geyikoglu F: Propolis prevents aluminium-induced genetic and hepatic damages in rat liver. Food and Chemical Toxicology: An International Journal Published For The British Industrial Biological Research Association 2010, 48:2741-2746.

43. Kaneto H, Nakatani $Y$, Kawamori D, Miyatsuka T, Matsuoka T, Matsuhisa M, Yamasaki Y: Role of oxidative stress, endoplasmic reticulum stress, and c-Jun $\mathrm{N}$-terminal kinase in pancreatic beta-cell dysfunction and insulin resistance. Int J Biochem Cell Biol 2006, 38:782-793.

44. Wu Z, Du Y, Xue H, Wu Y, Zhou B: Aluminum induces neurodegeneration and its toxicity arises from increased iron accumulation and reactive oxygen species (ROS) production. Neurobiology of aging 2012, 33(199):1-12

45. Ward RJ, Zhang Y, Crichton RR: Aluminium toxicity and iron homeostasis. J Inorg Biochem 2001, 87:9-14.

46. De Zwart LL, Meerman JH, Commandeur JN, Vermeulen NP: Biomarkers of free radical damage applications in experimental animals and in humans. Free Radic Biol Med 1999, 26:202-226.

47. Kaviarasan S, Naik G, Gangabhagirathi R, Anuradha C, Priyadarsini K: In vitro studies on antiradical and antioxidant activities of fenugreek (Trigonella foenum graecum) seeds. Food Chem 2007, 103:31-37.

48. Genet S, Kale RK, Baquer NZ: Alterations in antioxidant enzymes and oxidative damage in experimental diabetic rat tissues: Effect of vanadate and fenugreek (Trigonella foenum graecum). Mol Cell Biochem 2002, 236:7-12.

49. Kaviarasan S, Anuradha CV: Fenugreek (Trigonella foenum graecum) seed polyphenols protect liver from alcohol toxicity: a role on hepatic detoxification system and apoptosis. Die Pharmazie 2007, 62:299-304.

50. Kaviarasan S, Ramamurty N, Gunasekaran P, Varalakshmi E, Anuradha CV: Fenugreek (Trigonella foenum graecum) seed extract prevents ethanol-induced toxicity and apoptosis in Chang liver cells. Alcohol and alcoholism (Oxford, Oxfordshire) 2006, 41:267-273.

51. Gupta R, Nair S: Antioxidant flavonoids in common Indian diet. South Asian J. Prev. Cardio. 1999, 3:83-94.

52. Liu S, Hou W, Yao P, Li N, Zhang B, Hao L, Nüssler AK, Liu L: Heme oxygenase- 1 mediates the protective role of quercetin against ethanol-induced rat hepatocytes oxidative damage. Toxicology in vitro: an international journal published in association with BIBRA 2011, 1:1-7.

53. Tripathi UN, Chandra D: The plant extracts of Momordica charantia and Trigonella foenum graecum have antioxidant and anti-hyperglycemic properties for cardiac tissue during diabetes mellitus. Oxidative Med Cell Longevity 2009, 2:290-296.

54. Thirunavukkarasu V Anuradha CV Viswanathan P. Protective effect of fenugreek (Trigonella foenum graecum) seeds in experimental ethanol toxicity. Phytotherapy Res PTR 2003, 17:737-743.

55. Rao PU, Sesikeran B, Rao PS, Naidu AN, Rao W, Ramachandran EP: Short term nutritional and safety evaluation of fenugreek. Nutr Res 1996, 16:1495-1505. 
56. Gong Q-H, Wu Q, Huang X-N, Sun A-S, Shi J-S: Protective effects of Ginkgo biloba leaf extract on aluminum-induced brain dysfunction in rats. Life Sci 2005, 77:140-148.

57. Gabe M: Techniques Histologiques. Paris: Masson; 1986.

58. Pears A: Histochemistry, theoretical and applied. London: Churchill; 1985.

59. Buege JA, Aust SD: Microsomal lipid peroxidation. Methods Enzymol $1978,52: 302-310$.

doi:10.1186/1746-6148-9-22

Cite this article as: Belaïd-Nouira et al.: Fenugreek seeds, a

hepatoprotector forage crop against chronic $\mathrm{AlCl}_{3}$ toxicity. BMC

Veterinary Research 2013 9:22

\section{Submit your next manuscript to BioMed Central and take full advantage of:}

- Convenient online submission

- Thorough peer review

- No space constraints or color figure charges

- Immediate publication on acceptance

- Inclusion in PubMed, CAS, Scopus and Google Scholar

- Research which is freely available for redistribution 